\title{
O CAPITALISMO HUMANISTA COMO UM ELEMENTO PARA O DESENVOLVIMENTO: UM REGIME ECONÔMICO EM CONSONÂNCIA COM OS DIREITOS HUMANOS
}

\section{THE HUMANIST CAPITALISM AS AN ELEMENT FOR DEVELOPMENT: AN ECONOMIC SYSTEM IN ACCORDANCE WITH HUMAN RIGHTS}

\author{
${ }^{1}$ Flávia Moreira Guimarães Pessoa \\ ${ }^{2}$ Mariana Farias Santos
}

\section{RESUMO}

O presente artigo busca examinar o capitalismo humanista, a fim de demonstrar sua ligação com o direito ao desenvolvimento. Destarte, é a partir do método dedutivo, por meio da revisão bibliográfica, mormente da obra de Ricardo Sayeg e Wagner Balera, "O capitalismo humanista: filosofia humanista de direito econômico", que encontraremos respostas acerca desta nova forma de análise jurídica do capitalismo e de sua possibilidade de ser encarado como um elemento para o desenvolvimento. A fim de contextualizar este trabalho, será preciso examinar, ainda, o humanismo integral e a fraternidade, bem como teorias acerca do direito ao desenvolvimento.

Palavras-chave: Capitalismo humanista. Direito ao desenvolvimento. Fraternidade. Humanismo. Direitos humanos.

\begin{abstract}
The present article seeks to examine the humanist capitalism, in order to demonstrate its connection with the right of development. Thus, it is from the deductive method, through literature review, especially the literary work of Ricardo Sayeg and Wagner Balera, "The humanist capitalism: humanist philosophy of economic law", that we will find answers about this new form of legal analysis capitalism and its ability to be seen as an element for development. In order to contextualize this work, we need to examine also the integral humanism and fraternity, as well as theories about the right to development.
\end{abstract}

Keywords: Humanist capitalismo. Right to development. Fraternity. Humanism. Human rights.

\footnotetext{
${ }^{1}$ Doutora em Direito Público pela Universidade Federal da Bahia (UFBA), Salvador, Bahia, Brasil. Professora do Mestrado em Direito pela Universidade Federal de Sergipe (UFS), São Cristóvão, Sergipe, Brasil. Professora do Mestrado em Direitos Humanos pela Universidade Tiradentes (UNIT), Aracaju, Sergipe, Brasil. Email: tutortreinamento@gmail.com

${ }^{2}$ Mestranda em Direitos Humanos pela Universidade Tiradentes (UNIT), Aracaju, Sergipe, Brasil. Advogada. Email: marianafariasadv@gmail.com
} 


\section{1- INTRODUÇÃO}

O presente estudo busca verificar se o capitalismo humanista pode ser encarado como elemento para o desenvolvimento. Por esta razão, faz necessário, primeiramente, elucidar os conceitos, características e demais nuances de ambas as categorias aqui citadas. Por esta razão, iniciaremos o estudo através da compreensão do capitalismo humanista.

O capitalismo humanista é uma teoria recentemente desenvolvida por Ricardo Hasson Sayeg e Wagner Balera (2011), livres-docentes, em que se propõe uma nova vertente do capitalismo, enquanto regime econômico, de modo a garantir a concretização de direitos humanos de primeira, segunda e terceira dimensões, relativizando o direito à propriedade e à livre iniciativa. Não se trata de defender um novo modelo de comunismo ou de socialismo. Em nenhum momento, Sayeg e Balera propõem o fim do capitalismo.

Com efeito, trata-se de uma novel análise jurídica do regime capitalista, visto da perspectiva dos direitos humanos, com o objetivo de concretizar a dignidade da pessoa humana. Trata-se de uma vertente deste regime econômico que se coadune com a fraternidade, já que ambos estão previstos constitucionalmente.

Por consequência, será necessário traçar algumas considerações acerca da fraternidade, na medida em que esta será de crucial importância para a compreensão do assunto aqui analisado, uma vez que esta não será encarada como mero princípio constitucional carente de efetivação.

Outrossim, analisar-se-á o humanismo antropofilíaco - entendido por Sayeg e Balera como base da teoria que apresentam e como decorrente da mensagem de fraternidade levada por Jesus Cristo -, assim como far-se-ão aportes ao humanismo integral, a fim de facilitar a compreensão da linha de raciocínio traçada pelos autores para alcançarem o capitalismo humanista, situando a matéria aqui discutida. A partir da compreensão da teoria humanista do capitalismo, avançaremos a uma análise do direito ao desenvolvimento.

No que pertine ao direito ao desenvolvimento, faremos sua conceituação, apontando seus aspectos, alcance e previsão no plano de direito internacional, principalmente pela Declaração sobre o Direito ao Desenvolvimento, assim como transporemos o tema ao plano nacional. Além disso, exploraremos autores acerca do tema, a fim de contextualizar o estudo pretendido. Apontando, ainda, os desafios para sua implementação. 
Isto posto, o presente tema se justifica pelo fato de se mostrar em uma alternativa ao atual cenário de capitalismo predatório, permeado por um individualismo exacerbado, de modo a se verificar, inclusive, um meio de garantir o desenvolvimento sem macular o regime econômico sabidamente dominante.

Por fim, será traçada a conexão entre os temas individualmente analisados, com o fito de atestar a pertinência do capitalismo humanista como elemento para o desenvolvimento. Verificando, assim, a validade (ou não) da proposta que aqui se estuda.

Cumpre ressaltar que para a assunção destes objetivos será aplicado o método dedutivo, por meio da revisão bibliográfica dos autores que analisam e estruturam o capitalismo humanista, assim como de teóricos do direito ao desenvolvimento.

Passemos, então, à compreensão do capitalismo humanista.

\section{2- O CAPITALISMO HUMANISTA}

O capitalismo humanista diz respeito a uma novel teoria empreendida por Ricardo Hasson Sayeg e Wagner Balera, através da qual estes autores pretenderam apresentar uma nova análise jurídica do capitalismo frente a uma perspectiva de direitos humanos. Trata-se um novo olhar sobre o regime econômico prevalecente na pós-modernidade, a fim de consagrar a dignidade da pessoa humana. A teoria provém não só dos ditames da nossa Constituição Federal, interpretados de forma bastante humana, mas também de uma análise da evolução da sociedade, através do ideal de fraternidade difundido pelo cristianismo.

Inicialmente, é importante destacar que Sayeg e Balera, através da obra "O capitalismo humanista: filosofia humanista de direito econômico", publicada em 2011, baseiam a teoria aqui analisada no humanismo antropofilíaco, em oposição ao antropocentrismo e ao teocentrismo. Contudo, para chegar a este patamar, precisamos começar do mesmo ponto de partida que os autores, ou seja, "devemos partir de um novo marco teórico, que se estabelece antropologicamente no amor de Jesus Cristo, que nos uniu e nos leva ao encontro de Deus. [...] Esta é a Lei Universal da Fraternidade, que nos conduz com liberdade e igualdade para a democracia e a paz” (BALERA; SAYEG, 2011, p. 21).

Desta forma, é transposta para o capitalismo uma perspectiva humanista cristã, através do deslocamento da Lei Universal da Fraternidade para o Direito Econômico, na chamada filosofia humanista de Direito Econômico (BALERA; SAYEG, 2011, p. 25). O 
humanismo, por sua vez, segundo destacam Ricardo Sayeg e Wagner Balera (2011, p. 83), teve seus primórdios situados na civilização helênica, contudo, na Antiguidade, este tinha contornos aristotélicos, ou seja, se aplicava, tão somente, aos ditos cidadãos, os quais não incluíam os pobres, as mulheres e os escravos. Em contraposição a esta posição excludente, surge a fraternidade levada por Jesus Cristo.

A mensagem de fraternidade levada por Jesus Cristo é mais universal e instaura um humanismo antropofilíaco - cujo conceito explicitaremos a seguir. A dignidade humana pregada pelo Cristianismo abrange a igualdade de relações entre os homens, os quais não são apenas iguais, são também irmãos entre si e todos filhos do mesmo Deus. A fraternidade é posta, então, como valor absoluto do humanismo cristão (BALERA; SAYEG, 2011, p. 84).

Nesta senda, são relevantes as palavras de Carlos Augusto Alcântara Machado (2014, p. 36):

Para a época em que aparece e se desenvolve a doutrina - e ainda nos dias atuais - o sentido e o alcance do amor fraterno apresentam-se como uma profunda novidade, destacando-se como dom, absolutamente gratuito, sem resquício de vinculação à utilidade ou prazer. Logo, vai muito além da philía ou do eros grego.

Outra importante característica do amor fraterno cristão é a universalidade. É um amor dirigido a todos, sem exclusões de qualquer natureza e absolutamente gratuito. (grifos no original)

No entanto, em razão da sua raiz teocêntrica, o humanismo cristão proporcionou interpretações fundamentalistas, na Idade Média, as quais excluíam os não-cristãos (BALERA; SAYEG, 2011, p. 84). Aliada aos ideias iluministas, a fraternidade acaba por perder a sua centralidade (MACHADO, 2014, p. 44) e dá lugar a uma visão de humanismo individualista burguês, que acaba por colocar o homem como centro de todas as coisas (BALERA; SAYEG, 2011, p. 85).

É, justamente, no final da Idade Média que a efervescência cultural possibilita o repensar do homem e da humanidade, iniciando uma nova fase do humanismo. Surge, então, o movimento renascentista e com ele, o antropocentrismo, que acabou por levar ao fim da hegemonia cristã (MACHADO, 2014, p. 54).

Ocorre que colocar o homem como centro de tudo leva à banalidade, traduzida pelo hedonismo e egoísmo. Por isso, a via mais adequada seria o humanismo fraterno, inclusivo, evolucionista e emancipador, que proclama a concretização multidimensional dos direitos humanos e que não é teocêntrico, embora tenha Jesus Cristo como grande referência (BALERA; SAYEG, 2011, p. 102). Deste raciocínio surge, então, o humanismo antropofilíaco. É, justamente, esta vertente do humanismo que é utilizada como parâmetro 
para o capitalismo humanista, na medida em que acaba por propor a observância do outro e de sua dignidade.

Desta feita, Ricardo Sayeg e Wagner Balera (2011, p. 104) encontram substrato para sua teoria do capitalismo humanista no humanismo integral ${ }^{3}$ que, embora tenha em Jesus Cristo seu Mestre, face à infusão cultural de sua proposta sintetizada juridicamente na Lei Universal da Fraternidade, é posto a serviço de todos e de tudo, com independência de credo. Aqui, cabe a advertência de que o humanismo integral não pretende impor às pessoas a fraternidade pela via da convicção religiosa, tendo em vista que nem a fraternidade, nem a compaixão são virtudes exclusivas dos cristãos (BALERA; SAYEG, 2011, p. 100).

Assim, não se furta em reconhecer a fraternidade pelo mero argumento de diversidade de religião, posto que esta não se aplica, única e exclusivamente, aos cristãos, estendendo-se a todos, numa perspectiva de reconhecimento do outro como seu semelhante e tratando-o como gostaria de ser tratado.

A fraternidade se apresenta, assim, como uma boa alternativa ao que Bauman (2010, p. 08/09) denomina de capitalismo parasitário, isto é, o capitalismo, do mesmo modo que todos parasitas, prospera durante um período, com a condição de que ache um organismo que não tenha sido explora para que lhe seja fornecido alimento, mas não o faz sem prejudicá-lo, o que acaba por sepultar suas possibilidades de prosperidade ou de sobrevivência. Nesta senda, o agir fraterno se mostra um bom guia para este cenário parasitário e que sempre ocasiona prejuízo a alguém.

Nesta senda, é por meio da teoria do culturalismo jurídico que se pode afirmar a fraternidade, através do cristianismo, como valor síntese de nossa sociedade. Através deste raciocínio, desvenda-se o espírito objetivo da Lei Universal da Fraternidade, como o direito natural do qual resultam os direitos humanos, conformando a aplicação do direito positivo à potencialização elementar da dignidade humana, de acordo com o realismo jurídico (BALERA; SAYEG, 2011, p. 110).

Doutra senda, cumpre destacar que inserta na já inovadora teoria acerca do capitalismo humanista, Sayeg e Balera trazem uma interessante e inédita teoria acerca do que

\footnotetext{
${ }^{3}$ Consoante esclarece o Prof. Dr. Carlos Augusto Alcântara Machado (2014, p. 64): "A doutrina identificada como Humanismo Integral nasceu como resultado de lições [...] ministradas pelo filósofo francês Jacques Maritain na Universidade Internacional de Verão de Santander, em agosto de 1934.” Machado (2014, p. 67) prossegue esclarecendo que a imagem do homem, para o humanismo integral, é a de uma ser feito de matéria e espírito, não só do ser constituído de razão, mas também do ser enquanto pessoa. Apontando, ainda, que a "filosofia maritainiana advoga que o destino do homem e da humanidade é atingir a fraternidade universal" (MACHADO, 2014, p.72).
} 
chamam de aplicação quântica dos direitos humanos - cuja análise aqui passa a ter essencial importância, na medida em que pretendemos demonstrar a relação entre esta vertente do capitalismo e o direito ao desenvolvimento, direito humano. Ressaltando o indiscutível reconhecimento jurídico dos direitos humanos, tanto no plano internacional, quanto no plano nacional, os direitos humanos são relacionados ao humanismo antropofilíaco - base desta teoria acerca do regime capitalista (BALERA; SAYEG, 2011, p. 111).

Neste diapasão, a ordem jurídica deve dar conta da sagrada missão incutida pelo humanismo antropofilíaco, encorajando o reconhecimento dos direitos humanos, assim como de sua concretização, traduzindo-se na máxima de que o planeta será mas pacífico e civilizado, à medida em que se amplia a concretização desses direitos, considerando a dignidade universal da pessoa humana (BALERA; SAYEG, 2011, p. 13).

Este seria, então, o caminho para uma sociedade fraterna. Encarando, assim, a fraternidade como uma categoria jurídica, seguindo as lições do Prof. Dr. Carlos Augusto Alcântara Machado (2013, p. 79), cujas palavras aqui se faz relevante destacar a literalidade:

\footnotetext{
A fraternidade [...] deve ser compreendida, por certo, não exclusivamente como um elemento de fé ou mesmo de crença - apesar de entender que é exatamente no cristianismo que encontra seus fundamentos -, mas como uma virtude da cidadania, que supera as fronteiras da pátria ou da nação (cidadania interna), numa perspectiva universal de pessoa humana (cidadania global).

[...] outra não pode ser a conclusão: a Constituição Federal, efetivamente, consagrou a fraternidade como princípio-valor-categoria jurídica.
}

Pode-se afirmar, então, a existência de três dimensões dos direitos humanos, quais sejam, a igualdade inata; a liberdade inata; e fraternidade inata, que seria o valor consubstancial do homem e de todos os homens. Esta tríade refere-se aos elementos estruturantes de um só núcleo, que seria a dignidade, isto é, a humanidade imanente ao homem e a todos os homens, e que atribui objetivamente à pessoa humana valor por si. No entanto, deve-se advertir que estas dimensões não se sucedem ou se sobrepõem, mas se adensam. Destacando que os direitos humanos devem ser executados como uma universalidade jurídica, não sendo admissível a sua ruptura (BALERA; SAYEG, 2011, p. 117/118).

A concretização desses direitos humanos se daria, então, por meio do método quântico, o qual confirma que a composição elementar da norma jurídica positivada seria o direito natural sedimentado, e que os direitos humanos, por sua vez, constituem o direito natural universalmente admitido. Esta teoria bastante arrojada traça uma relação direta entre matéria, energia e densidade; e direito positivo, direitos humanos e realismo, respectivamente, 
através de uma análoga à fórmula de Albert Einstein acerca da teria da relatividade (BALERA; SAYEG, 2011, p. 120).

É possível concluir, assim, que toda norma jurídica positiva equivale quanticamente a uma norma de direitos humanos, cuja aplicação satisfaz a dignidade da pessoa humana. Nesta medida, "por imposição da Lei Universal da Fraternidade, não existe solução de direito que contrarie o direito objetivo da dignidade da pessoa humana, de acordo com o realismo jurídico" (BALERA; SAYEG, 2011, p. 124).

Feitos tais esclarecimentos acerca do humanismo antropofilíaco e da Lei Universal da Fraternidade, enquanto bases do capitalismo humanista, urge transpor estas lições ao âmbito do domínio econômico, uma vez que a dignidade da pessoa humana ou existência digna tem, por óbvio, implicações econômicas. Aproximando-nos, ainda mais, da individuação do capitalismo humanista.

Cumpre salientar, neste particular, que, "para o humanismo antropofilíaco, a ordem econômica deve ser evolucionista, inclusiva e emancipadora [...] - em resumo, fraterna e, em especial, misericordiosa ao se confrontar com a miséria” (BALERA; SAYEG, 2011, p. 137). Desta forma, face ao inconteste fato do domínio do capitalismo em todo mundo, não existindo qualquer reduto socialista relevante, temos que, em razão da eficiência de seus agentes econômicos, em busca de seus próprios interesses, o capitalismo acabou por prevalecer, consoante destacam Balera e Sayeg (2011, p. 141).

Daí a grande relevância deste novo marco teórico, haja vista que pretende concretizar os direitos humanos e a fraternidade sem macular os princípios e o regime econômico que, sabidamente, domina o planeta. Não se trata, desse modo, de um meio de subverter a ordem econômica vigente, mas sim de adequá-la a parâmetros fraternos e que resguardem os menos favorecidos, inclusive, posto que estes são os mais vulneráveis aos reveses do capitalismo predatório que se vem praticando.

Por esta razão, Ricardo Hasson Sayeg (2009, p. 1365), em ensaios preliminares sobre o tema que acabou por virar a tese de sua livre-docência, apresentou importantes conclusões acerca da inaplicabilidade da Análise Econômica do Direito ao Brasil:

[...] não podemos cair na armadilha de aplicar no Brasil a Análise Econômica do Direito conforme a Escola de Chicago, pois sua implementação implicará um Estado liberal promotor de um liberalismo econômico sem freios e calibragem sociopolíticos, provocando um desmantelamento das nossas, ainda insuficientes, contudo concretas, realizações dos objetivos fundamentais da República e das decorrentes conquistas políticas, sociais e culturais, ao arrepio do princípio 
constitucional implícito da proibição de retrocesso social, consagrado no art. $5^{\circ}$, inciso XLI, c.c. os arts. $3^{\circ}$ e $6^{\circ}$, todos da Constituição Federal. ${ }^{4}$

Em arremate, Sayeg (2009, p. 1365) conclui que o Brasil não possui condições de sustentabilidade democrática apta a conservar um ambiente neoliberal em um Estado liberal com seus efeitos perversos de exclusão social, em negação dos direitos humanos de primeira e segunda dimensão. Assim, demonstra-se, por meio do estudo de dispositivos constitucionais, que a nossa Carta Magna não estabelece um Estado liberal, tampouco um Estado intervencionista do bem-estar social.

Em oposição, uma análise do art. 170 da Constituição Federal de 1988, permite afirmar que o regime econômico deve observar, no Brasil, as determinações ali ínsitas, acerca de uma ordem econômica, alicerçada na valorização do trabalho e na livre-iniciativa, assegurando, a todos, existência digna conforme os ditames da justiça social, com o objetivo de concretizar os direitos sociais a toda a população, observando-se todos os princípios constitucionais (SAYEG, 2009, p. 1366). Ricardo Sayeg (2009, p. 1367) acrescenta, ainda, que a nossa constituição adota o capitalismo como regime econômico, todavia uma vertente indutora da livre iniciativa e da propriedade privada, objetivando o alcance dos objetivos fundamentais da República, além de tornar realidade os direitos humanos de segunda e terceira dimensões, mormente os direitos sociais.

Assim, é possível destacar o chamado Estado Brasileiro da Fraternidade, cuja incumbência e garantir a todos um mínimo vital, pautado numa perspectiva multidimensional de direitos humanos de primeira, segunda e terceira dimensões, conforme preleciona a nossa Constituição (SAYEG, 2009, p. 1368).

Traçando melhores contornos do que seria o capitalismo humanista - e retornando à obra principal aqui analisada -, cumpre aqui destacar que, para Sayeg e Balera (2011, p. 169), não há, na economia de mercado, uma compaixão apta a consagrar a fraternidade, tendo em vista que se trata de um ambiente em que domina a lei da seleção natural, um estado selvagem da natureza, não condizente com o que hoje temos como marco civilizatório da humanidade.

\footnotetext{
${ }^{4}$ Aqui, cabe fazer um esclarecimento acerca do desaconselhamento, por parte de Sayeg, acerca da aplicabilidade, advertindo que, sendo o Brasil um Estado Democrático, nem o Estado do bem-estar social, nem o Estado liberal são sustentáveis, face ao ideal democrático de total inclusão populacional, ainda que tenha um perfil liberal. Argumenta, nesse sentido, que o Welfare State, em razão da falta de recursos para atendimento de toda a população, implicaria em exclusão social em decorrência da ruína econômica e carência de disponibilidades, o que acabaria causando a asfixia da livre-iniciativa capitalista. O Estado Liberal, por sua vez, diante do mesmo efeito excludente por relegar à própria competitividade, a inclusão social das gentes (SAYEG, 2009, p . 1365).
} 
Desta feita, citando Bauman (1998) e Ammann (2003), os idealizadores do capitalismo humanista ressaltam a inadmissibilidade da exclusão social, haja vista que a pobreza é encarada como não-cidadania, sem mencionar a criminalização da pobreza. Todos são atingidos pelo menosprezo da economia de mercado em relação ao planeta, tal como aconteceu com o desastre ambiental ocorrido no golfe do México, além do fato de que a humanidade padece com a restrição geográfica, que cada vez mais represa pobreza e impede que os migrantes de países em desenvolvimento adentrem no território dos países desenvolvidos (BALERA; SAYEG, 2011, p. 170/171). ${ }^{5}$

Daí a importância da associação do humanismo antropofilíaco ao regime capitalista, que tem o encargo de avançar a partir do neoliberalismo e, ao direito, a incumbência de empregar a teoria da análise econômica do direito, face às externalidades ${ }^{6}$ negativas e do desequilíbrio horizontal dos direitos. Asseverando que a economia de mercado só funciona a contento quando não vai de encontro ao humanismo antropofilíaco (BALERA; SAYEG, 2011, p. 172/173) Sayeg e Balera (2011, p. 176) indicam, então, o caminho que o capitalismo deve seguir, guiado por uma economia humanista de mercado, legitimando, assim, uma análise humanista do direito econômico.

Estão, assim, expostas as bases para a teoria do capitalismo humanista. Razão pela qual, importa destacar a literalidade das palavras de Ricardo Sayeg e Wagner Balera (2011, p. 180) ao conceituarem o seu objeto de estudo e destacarem seu objetivo:

[...] ajustado à lei natural da fraternidade, o capitalismo deve ser indutor do exercício do direito subjetivo natural de propriedade, com o fim de concretização dos direitos humanos de primeira, segunda e terceira dimensões, para a satisfação universal do direito objetivo de dignidade do homem todo e de todos os homens da presente e das futuras gerações: um liberalismo econômico renovado pelo humanismo antropofilíaco e delineado a partir da situação concreta de cada país, quanto à economia de mercado, conforme a realidade político-econômico-social e a cultura local-global.

[...] Garantido o modo de vida das pessoas, cumpre ao regime jus-econômico, insuflado pelo humanismo antropofilíaco e inserido numa economia de mercado, assegurar a todos ao mesmo tempo o mínimo necessário à vida para a satisfação da dignidade humana [...] e consecução de um planeta digna: livre, pacífico, sustentado e desenvolvido.

\footnotetext{
${ }^{5}$ Neste ponto da argumentação dos idealizadores do capitalismo humanista, conseguimos transpor seus argumentos para o atual momento mundial, recordando da a catástrofe ocorrida na Mineradora Samarco, em Mariana e da restrição de entrada dos refugiados sírios da Europa. O que só reforça a teoria aqui estudada, na medida em que é possível vislumbrar, no dia-a-dia, cada um dos elementos que os levam a defender esta vertente do regime econômico, até mesmo como um meio para o desenvolvimento, como será demonstrado a seguir.

${ }^{6}$ Sayeg (2009, p. 1359) denomina externalidades as repercussões, em caráter privado, que atingem a esfera de direitos de outra pessoa determinada, em seus direitos individuais ou/e em caráter social, quando atinge a coletividade em seus direitos difusos e coletivas. Classificando-as em positivas e negativas, isto é, úteis ou indesejáveis, respectivamente.
} 
Doutra senda, é relevante ressaltar que, com a finalidade de concretizar a teoria acerca do capitalismo humanista, decorrente de uma interpretação sistêmica dos dispositivos constitucionais, com amparo em norma internacionais, há uma Proposta de Emenda à Constituição tramitando na Câmara dos Deputados (PEC 383/2014). Esta PEC objetiva dar nova redação ao artigo 170 da Carta Magna, inserindo a observância dos direitos humanos entre os princípios que regem a ordem econômica.

Ricardo Sayeg (2012, p. 11) escreveu, inclusive, denso artigo científico acerca de "Uma proposta de emenda constitucional para o capitalismo humanista na Constituição Federal", defendendo a existência, na nossa ordem jurídica, de um perfil constitucional do capitalismo humanista brasileiro, acrescendo um inciso ao art. 170, CF - Inciso Xprevalência dos direitos humanos -, consagrando a teoria aqui estudada, de forma expressa, na Carta Magna. Atualmente, a PEC supracitada encontra-se em trâmite na Câmara dos Deputados, pronta para Pauta na Comissão de Constituição e Justiça e de Cidadania. Aguardemos, então, o deslinde da matéria, ansiando que seja reconhecida a base constitucional da teoria aqui estudada, agora de forma expressa na $\mathrm{CF}$.

Perfeitamente delineado, assim, o capitalismo humanista - primeira vertente a ser examinada neste estudo -, resta-nos, neste momento, passar à análise do direito ao desenvolvimento, com vistas a atingir o ponto fulcral deste artigo científico, relacionando os dois objetos estudados: demonstrar o capitalismo humanista como elemento para o desenvolvimento.

\section{3- DIREITO AO DESENVOLVIMENTO E O CAPITALISMO REGIDO PELO HUMANISMO ANTROPOFILÍACO}

Primeiramente, antes mesmo de empreender qualquer comparativo entre o direito ao desenvolvimento e o capitalismo humanista, mister se faz analisar o direito ao desenvolvimento, expondo seus aspectos relevantes para a compreensão da conexão que aqui se pretende delinear. Passemos, então, ao direito ao desenvolvimento.

O direito ao desenvolvimento teve sua primeira manifestação jurídico-normativa, no plano internacional, com a Resolução no 41/128 da Assembleia Geral das Nações Unidas (MARQUES; OLIVEIRA; SÁTIRO, 2015, p. 03), é a chamada Declaração sobre o Direito ao 
Desenvolvimento de 1986. No entanto, a primeira vez em que foi utilizada a nomenclatura 'direito ao desenvolvimento'7 data de 1972, por Keba Mbaye, ministro da corte suprema do Senegal, na aula inaugural do Instituto Internacional de Direitos do Homem (MARQUES; OLIVEIRA; SÁTIRO, 2015, p. 06).

Flávia Piovesan (2010, p. 65/67) aponta a concepção contemporânea dos direitos humanos introduzida pela Declaração Universal dos Direitos Humanos (1948), ao situar o direito aqui estudado. Demonstrando que esta concepção decorre do movimento de internacionalização dos direitos humanos, surgida no pós-guerra, responsável pelo caráter de universalidade e indivisibilidade desses direitos. O que possibilitou a estruturação de um sistema internacional de proteção desses direitos, integrado por tratados, convenções e sistemas regionais de proteção.

O grande feito da Declaração foi consagrar as diversas perspectivas do direito ao desenvolvimento, através de seu art. $1^{08}$, o qual consagra o direito de participação do sujeito no desenvolvimento social, humano, cultural, econômico, científico, ambiental e político, encarando, assim, o indivíduo como um sujeito de direitos e como um fim em si mesmo (MARQUES; OLIVEIRA; SÁTIRO, 2015, p. 06/07). Neste sentido, Piovesan (2002, p. 05/06) identifica, na Declaração de 1986, três aspectos do direito ao desenvolvimento: a importância da participação; a necessidades básicas de justiça social; e necessidade de adoção de programas e políticas nacionais, assim como de cooperação internacional. Conclui, assim, que o direito ao desenvolvimento reivindica uma globalização ética e solidária.

Outrossim, também é de relevante importância para a matéria, a Declaração de Direitos Humanos de Viena (1993), que reiterando a Declaração de 1948, afirma a interdependência entre os valores de direitos humanos, democracia e desenvolvimento. Não existem direitos humanos sem democracia, e vice-versa. O regime mais compatível com os direitos humanos e sua proteção é o regime democrático (PIOVESAN, 2010, p. 68).

\footnotetext{
${ }^{7}$ Aqui, é importante destacar a diferenciação apontada por Marques, Oliveira e Sátiro (2015, p. 05) entre o Direito Internacional do Desenvolvimento (DID) e o Direito Humano ao Desenvolvimento (DHD). Correspondendo o primeiro a uma organização jurídica na qual se intenta regular as relações entre os Estados. O DHD, por sua vez, refere-se a um direito humano, haja vista a identificação do sujeito como um participante ativo do processo de desenvolvimento, considerando-se as dimensões coletiva e individual de direitos.

${ }^{8}$ Declaração sobre o direito ao Desenvolvimento (ONU, 1986) - Artigo $1^{\circ}-1$. O direito O direito ao desenvolvimento é um direito humano inalienável em virtude do qual toda pessoa humana e todos os povos estão habilitados a participar do desenvolvimento econômico, social, cultural e político, a ele contribuir e dele desfrutar, no qual todos os direitos humanos e liberdades fundamentais possam ser plenamente realizados. 2. O direito humano ao desenvolvimento também implica a plena realização do direito dos povos de autodeterminação que inclui, sujeito às disposições relevantes de ambos os Pactos Internacionais sobre Direitos Humanos, o exercício de seu direito inalienável de soberania plena sobre todas as suas riquezas e recursos naturais.
} 
Nada obstante a relevância da Declaração de 1968, esta sofre questionamentos quanto à existência ou não, propriamente, do direito ao desenvolvimento. Senão, vejamos.

\begin{abstract}
A Declaração sobre o Direito ao Desenvolvimento vem deixando um rastro de controvérsia desde que foi aprovada pelas Nações Unidas, em 1986. Enquanto os países em desenvolvimento do Sul argumentavam em favor de uma transferência de recursos como base para o direito ao desenvolvimento, os países desenvolvidos, representando o Norte, negavam a existência de tal direito. Contudo, a reafirmação do direito ao desenvolvimento por ocasião da Conferência Mundial sobre Direitos Humanos realizada em Viena, em 1993, proporcionou uma oportunidade para que o debate se deslocasse da retórica para uma efetiva implementação. (NWAUCHE; NWOBIKE, 2005, p. 97)
\end{abstract}

No entanto, mesmo com a linha argumentativa que não considera que o direito humano ao desenvolvimento se alicerça em um tratado ou convenção internacional que o legitime, de forma individual, como um direito humano, sua previsão na Declaração de 1986, a qual não detém cunho jurídico vinculante perante os Estados, não necessariamente denota uma ilegitimidade jurídica, haja vista que existem diversas convenções constitutivas de organizações globais e regionais, bem como tratados internacionais que trazem esse direito de forma expressa e incondicionada (MARQUES; OLIVEIRA; SÁTIRO, 2015, p. 10).

Reconhecendo o caráter de soft law da Declaração sobre o Direito ao Desenvolvimento, Flávia Piovesan (2010, p. 74) sugere o emprego de um instrumento com força jurídica vinculante, a fim de robustecer a vertente internacional do direito ao desenvolvimento. O que contribuiria, inclusive, segundo a autora, para a solidificação de um regime jurídico de direitos que se aplicasse ao direito aqui estudado.

No entanto, face ao atual cenário de resistência dos países desenvolvidos em reconhecer o caráter vinculante do direito ao desenvolvimento, a opinião das autoras Marques, Oliveira e Sátiro, acima explicitada, nos parece mais condizente com os direitos humanos, ao reconhecer a previsão deste direito em diversas outras convenções e tratados, de forma expressa.

Transpondo o tema ao plano nacional, cumpre destacar que a Constituição Federal "referencia o desenvolvimento no próprio preâmbulo ao enunciar que o Estado democrático brasileiro, que se institui a partir desta Carta, está compromissado dentre outros fins, a assegurar o desenvolvimento da sociedade brasileira" (FERRARO; PEIXINHO, 2007, p. 6961). Além do preâmbulo, o desenvolvimento é alçado a um dos objetivos da República, no art. $3^{\circ}$ da $\mathrm{CF}$, o que exige, por parte do Estado, diretrizes cogentes às ações públicas, com o 
fito de dar efetividade aos poderes que foram constituídos pela Carta Magna (FERRARO; PEIXINHO, 2007, p. 6961).

Sem embargo da assertiva previsão constitucional, esta não condiz com a concepção com que merece ser difundido o direito ao desenvolvimento, na medida em que este é enunciado, tal como um programa de ação do governo, em prejuízo da visão integral e indivisível do sujeito que merece o desenvolvimento em todas as suas acepções (MARQUES; OLIVEIRA; SÁTIRO, 2015, p. 13).

Doutra senda, aqui cabe acrescentar importante contribuição doutrinária acerca do direito ao desenvolvimento, trazendo à baila a visão do "Desenvolvimento como Liberdade", obra de Amartya Sen. Razão pela qual, é importante destacar que, na visão de Amartya Sen (2010, p.16), o desenvolvimento é encarado como um processo de expansão das liberdades reais de que os indivíduos desfrutam. Nesta medida, mister que sejam removidos as principais fontes de privação de liberdade, tais como pobreza, tirania, escassez de oportunidades econômicas e destituição social sistemática, além de descuido com os serviços públicos e intervenção demasiada de Estados repressivos.

Não só isso. Amartya Sen (2010, p. 29) afasta a óbvia relação traçada, leigamente, entre desenvolvimento e acumulação de patrimônio, ao afirmar que o desenvolvimento deve estar ligado à melhoria da vida que as pessoas levam, bem como das liberdades que desfrutam. Para este autor, a liberdade é elemento essencial do desenvolvimento, sendo este diretamente dependente daquele, mormente quanto aos direitos humanos, objetivando-se, sempre, o alargamento dessas liberdades (SEN, 2010, p. 56).

Nesta medida, o desenvolvimento está diretamente relacionado à expansão das capacidades/liberdades das pessoas, possibilitando-lhes participar da vida política, social e econômica e demais aspectos, de forma ativa e consciente (SEN, 2010, p. 16).

Avançando um pouco na seara do desenvolvimento, insta destacar o conceito de desenvolvimento humano sustentável apresentado por Marielza Oliveira (2006, p. 05):

Em poucas palavras, o conceito de Desenvolvimento Humano Sustentável abrange meios e fins; justiça social e desenvolvimento econômico; bens materiais e o bemestar humano; investimento social e o empoderamento das pessoas; atendimento das necessidades básicas e estabelecimento de redes de segurança; sustentabilidade ambiental para as gerações atuais e futuras; e a garantia dos direitos humanos civis, políticos, sociais, econômicos e ambientais.

Uma estratégia DHS de desenvolvimento considera cada questão, inclusive a expansão da economia, do ponto de vista da população. Cada iniciativa deve ser avaliada em termos do grau de participação das pessoas e do benefício que traz para elas. Os fatores sociais, políticos e culturais devem receber a mesma atenção que os 
fatores econômicos. Visto assim, o desenvolvimento é um fenômeno com muitas dimensões, e não apenas a econômica.

Desta feita, mais uma vez, é destacado que a vertente econômica não importa, necessariamente, em desenvolvimento. Sendo este um conceito com espectro significativo muito mais amplo, abrangendo, inclusive, liberdades e capacidades pessoais, democracia, garantias de direitos humanos e participação ativa e consciente na vida política. O que, diretamente, conecta este conceito ao capitalismo humanista, na medida em que este intenta implementar uma nova vertente do capitalismo, enquanto regime econômico, de modo a garantir a concretização de direitos humanos de primeira, segunda e terceira dimensões.

Esclarecidos, então, os aspectos acerca do direito ao desenvolvimento, cumpre relacioná-lo ao capitalismo humanista. Demonstrando se este pode ser encarado como um elemento para a consecução ou para a contribuição ao direito ao desenvolvimento.

Neste diapasão, considerando que o Programa das Nações Unidas tem destacado que as pessoas são a real riqueza das nações, não a restringindo ao crescimento econômico ou ao PIB (Produto Interno Bruto). Assim, são países desenvolvidos aqueles em que todo o povo está inserido na evolução política, econômica, social e cultural, atingindo patamares que atendam ao mínimo vital; são os países inclusivos e emancipadores. (BALERA; SAYEG, 2011, p. 177)

Segundo Sayeg e Balera (2011, p. 178/179), sendo o regime econômico adotado excludente há uma violação à dignidade da pessoa humana, equivalendo à pena banimento, sem que tenha havido qualquer crime. Assim sendo, não é recomendável a adoção do regime neoliberalista ou de economia de mercado para países periféricos, por exemplo, sob pena de violações à dignidade da pessoa humana Sendo exigível, muitas vezes, a intervenção do estado para corrigir estas situações indesejáveis.

Por esta razão, a fim de satisfazer "preferencialmente a dignidade da pessoa humana da presente e das futuras gerações, a disponibilidade dos esforços e dos recursos econômicos, públicos e privados, deve ser submetida ao indispensável juízo humanista antropofilíaco" (BALERA; SAYEG, 2011, p. 180). A importância da Lei Universal da Fraternidade na ponderação sobre a disponibilidade dos recursos supracitados é fundamental para a garantia dos direitos humanos, assim como para as capacidades e liberdades dos sujeitos individualmente considerados. 
Aqui, cumpre destacar a literalidade do conceito resumido de Balera e Sayeg (2011, p. 184) acerca de seu objeto de estudo, o qual, por si só, já demonstra o cumprimento dos elementos aqui apontados como necessários para o desenvolvimento, não só no viés normativo, mas também de acordo com as lições de Amartya Sen, possibilitando o desenvolvimento das potencialidades do indivíduo ao máximo:

[...] é o regime jus-econômico do capitalismo humanista, instituidor da economia humanista de mercado e construído a partir da ideia de predomínio da liberdade calibrada pela igualdade na regência da fraternidade, dentro da ampla perspectiva de concretização multidimensional dos direitos humanos que assegura, a um só tempo, um planeta digno e o acesso a níveis dignos de subsistência para o homem todo e todos os homens.

Neste passo, a conclusão a que se pode chegar, por meio do novo marco teórico aqui estudado, é a de um capitalismo que contempla e respeita os direitos humanos, assegurando a satisfação da dignidade humana e a conquista de um planeta digno, isto é, livre, pacífico, sustentado e desenvolvido. Trata-se de uma "solução econômica capitalista sob o tríplice ideal adensado de liberdade, igualdade e fraternidade [...], um capitalismo entendido e regido pela ótica dos direitos humanos multidimensionalmente adensados e considerados para o fim da satisfação da dignidade da pessoa humana e do planeta" (BALERA; SAYEG, 2011, p. 183) Ora, é um meio de consecução do direito ao desenvolvimento, nos moldes aqui vistos.

O cotejo das informações aqui apresentadas leva à óbvia conclusão de que o capitalismo humanista, enquanto regime econômico preocupado com os direitos humanos, é sim um meio de possibilitar o direito ao desenvolvimento. Confirmando, por conseguinte, a proposta apresentada neste estudo. Podendo-se dizer, em suma, que o capitalismo humanista é um elemento para o desenvolvimento.

\section{3- CONSIDERAÇÕES FINAIS}

O capitalismo humanista, vertente do regime econômico baseada no humanismo antropofilíaco, se apresenta como uma possibilidade da economia sob a influência da igualdade, liberdade e fraternidade, respeitando a dignidade da pessoa humana e voltada para a efetivação dos direitos humanos. Decorre, consoante acima exposto, de uma interpretação sistemática da nossa Constituição Federal, mormente da garantia da dignidade da pessoa humana, a previsão de uma sociedade fraterna e do dispositivo acerca da ordem econômica. É uma meta já constante na Carta Magna. Sua constitucionalidade é, pois, inconteste. 
Nesta medida, ainda que haja Proposta de Emenda Constitucional prevendo a disposição expressa da prevalência dos direitos humanos no art. 170, CF, esta denota mera formalidade, com o fito de tornar expresso raciocínio decorrente da interpretação das disposições constitucionais.

É um regime econômico que pensa e considera o sujeito em sua singularidade, assim como de forma coletiva. Há uma preocupação com os reflexos das políticas econômicas na vida das pessoas, pensando em sua dignidade. Desta forma, o capitalismo humanista ultrapassa o que usualmente se entende como desenvolvimento, isto é, mera acumulação de riquezas, na medida em que se preocupa com a vida digna e com a garantia dos direitos humanos. É, sobretudo, um meio de alcançar desenvolvimento.

Assim, tendo em vista que o direito ao desenvolvimento enfrenta o desafio quanto a sua concretude e força jurídica vinculante, como acima destacado, a adoção do capitalismo humanista, tanto decorrente de uma interpretação sistêmica do texto constitucional, quanto se considerando a Proposta de Emenda Constitucional supracitada, figuraria num modo de garantir meios para atingir o desenvolvimento, uma vez que esta vertente do regime capitalista já é, por si só, um elemento para o desenvolvimento, como também porque se apresenta como uma forma de garantir a dignidade da pessoa humana, o equilíbrio do meio ambiente, além de uma perspectiva mais ampla de direitos humanos.

O capitalismo humanista se mostra, então, como um modo de viabilizar o direito ao desenvolvimento, de forma cogente e efetiva. Figurando, inclusive, como um instrumento para guiar a atuação do Estado rumo ao desenvolvimento. Como já dito, é possível afirmar, sim, que o capitalismo humanista é um elemento para o desenvolvimento.

\section{REFERÊNCIAS BIBLIOGRÁFICAS}

BALERA, Wagner; SAYEG, Ricardo Hasson. O capitalismo humanista: filosofia humanista de direito econômico. Petrópolis: KBR, 2011.

BAUMAN, Zygmunt. Capitalismo parasitário: e outros temas contemporâneos. Rio de Janeiro: Jorge Zahar Ed., 2010.

BRASIL. Proposta de Emenda Constitucional no 383/2014. Lex: Brasília, DF, 20 de fevereiro de 2014. Disponível em:

http://www.camara.gov.br/proposicoesWeb/prop_mostrarintegra;jsessionid=546A4DF0AD71A03665 CDEF52F34A778E.proposicoesWeb1 ?codteor $=1230534 \&$ filename $=P E C+383 / 2014$. Acesso em: 16/06/2016, às 16:00.

MACHADO, Carlos Augusto Alcântara. A garantia constitucional da fraternidade: constitucionalismo fraternal. 2014. 272 f. Tese (Doutorado em Direito) - Pontifícia Universidade Católica de São Paulo, São Paulo, 2014.

Revista de Direito, Economia e Desenvolvimento Sustentável | e-ISSN: 2526-0057 | Curitiba | v. 2 | n. 2 | p. 204 - 220 | Jul/Dez. 2016. 
MACHADO, Carlos Augusto Alcântara. A fraternidade e o Direito Constitucional brasileiro: Anotações sobre a incidência e aplicabilidade do princípio/valor fraternidade no Direito Constitucional brasileiro a partir de sua referência no preâmbulo da Constituição Federal de 1988. In: Fraternidade como categoria jurídica. Vargem Grande, SP: Cidade Nova, 2013, p. 63/79.

MARQUES, Verônica Teixeira; OLIVEIRA, Liziane Paixão Silva; SÁTIRO, Guadalupe Souza. O reconhecimento jurídico do direito ao desenvolvimento sob a perspectiva emancipatória dos direitos humanos/the juridical recognition of the right to development according to the emancipatory perspective of human rights. Revista Jurídica Eletrônica da UFPI, v. 2, n. 02, 2016. Disponível em: http://www.ojs.ufpi.br/index.php/raj/article/view/4669. Acesso em: 16/06/2016, às 17:10.

NWAUCHE, Eniynna S.; NWOBIKE, Justice C. Implementação do direito ao desenvolvimento. Sur Revista Internacional de Direitos Humanos, p. 97, 2005. Disponível em: http://www.scielo.br/pdf/sur/v2n2/a05v2n2.pdf. Acesso em: 15/06/2016, às 15:35.

ORGANIZAÇÃO DAS NAÇÕES UNIDAS. Declaração sobre o direito ao desenvolvimento. 1986. Disponível em: http://www.direitoshumanos.usp.br/index.php/Direito-ao-

Desenvolvimento/declaracao-sobre-o-direito-ao-desenvolvimento.html. Acesso em: 16/06/2016, às 17:00.

OLIVEIRA, Marielza. O desenvolvimento humano sustentável e os objetivos de desenvolvimento do milênio. RECIFE/PE. Desenvolvimento humano no Recife: Atlas Municipal. Seção SecretariasPlanejamento Participativo e Obras-Projetos e Ações. Disponível em: http://www. recife. pe. gov. $\mathrm{br} / \mathrm{pr} / \mathrm{sec}$ lanejamento/pnud2006/doc/analiticos/desenvolvimentoh umano. pdf. Acesso em: 16/06/2016, 00:13.

PEIXINHO, Manoel Messias; FERRARO, Suzani Andrade. Direito ao desenvolvimento como direito fundamental. In: XVI Congresso Nacional do CONPEDI. 2007. p. 6963. Disponível em: http://www.publicadireito.com.br/conpedi/manaus/arquivos/anais/bh/manoel_messias_peixinho.pdf. Acesso em: 15/06/2016, às 18:50.

PIOVESAN, Flávia Cristina. Direito ao Desenvolvimento. 2010. Disponível em: http://www.dhnet.org.br/direitos/militantes/flaviapiovesan/piovesan_direito_ao_desenvolvimento.pdf. Acesso em: 14/06/2016, às 13:34.

PIOVESAN, Flávia Cristina. Direito ao desenvolvimento: desafios contemporâneos. In: PIOVESAN, Flávia; SOARES, Inês Virgínia Prado (Coord.). Direito ao desenvolvimento. Belo Horizonte: Fórum, 2010.

SAYEG, Ricardo Hasson. O capitalismo humanista no Brasil. In: MIRANDA, Jorge; SILVA, Marco Antonio Marques da. In: Tratado luso-brasileiro da dignidade humana. $2^{\mathrm{a}}$ Ed. São Paulo: Quartier Latin, 2009, p. 1355/1370.

SAYEG, Ricardo. Uma proposta de emenda constitucional para o capitalismo humanista na constituição federal. Revista Jurídica da Escola Superior do Ministério Público de São Paulo, v. 1, p. 09-31, 2012. Disponível em:

http://www.esmp.sp.gov.br/revista_esmp/index.php/RJESMPSP/article/view/14. Acesso em: Acesso em: 16/06/2016, às 16:04.

SEN, Amartya. Desenvolvimento como liberdade. São Paulo: Companhia das Letras, 2010. 